\title{
Towards guidelines for withholding and withdrawal of life prolonging treatment in neonatal medicine
}

\author{
Len Doyal, Daniel Wilsher
}

Despite being a focus of public debate for over 20 years, neonatal medicine continues to produce acute ethical dilemmas. ${ }^{1}$ During this period great advances in treatment have made it possible to save many more infants. Sometimes, however, serious harm can result from prolonging the lives of some who are severely damaged, a potentially traumatic experience for all involved in their care.

Decisions to withhold or to withdraw treatment - what we shall call 'selective nontreatment' for the purposes of this paper - are sometimes made in these circumstances. The ethical criteria employed in making such difficult choices are rarely articulated or explicitly justified, being left largely to the discretion of individual clinicians. The problem which this poses is that clinicians do not always agree. Given the obvious importance of these decisions for all those involved, further clarification about what constitutes good moral practice is essential.

Considerable uncertainty as regards the law also exists. Although rare, criminal prosecution for non-treatment is not unknown. Until recently, English law left doctors in peril as to what was acceptable practice. In 1981, for example, Leonard Arthur was tried for attempted murder for acting on the belief that non-treatment of an infant with Down's syndrome who had been rejected by his parents was justified. ${ }^{2}$ Since 1989 , however, a series of court cases have substantially clarified the legal position. Now there are a range of situations in which selective non-treatment can more confidently be said to be lawful.

Provided, therefore, that convincing arguments can be developed that morally justify this body of case law, ethical and legal guidelines on selective non-treatment could in principle be formulated. These might then be used to inform negotiations within neonatal units about those infants being considered for non-treatment. In the following paper, we attempt to provide a moral and legal framework within which such guidelines might be developed.

\section{The duty of care}

When doctors undertake to treat a patient they assume a moral and legal duty of care. The nature and scope of their obligation can be reduced to the following two principles. First, the life and health of patients must be protected to an acceptable standard. In practice this means that doctors must act in the patient's best interests as defined by a competent body of medical opinion. Second, respect must also be shown for the autonomy of patients - their moral and legal right to control their own destiny. Again, this must be done to a reasonable professional standard. ${ }^{3}$ In the case of neonates, of course, parents assume this right through exercising informed consent to treatment on behalf of their child.

The only acceptable legal and ethical justification for deviating from the general obligation to provide life saving care is that doing so is in the patient's best interests. This is important because, in practice, many other arguments are used to justify selective non-treatment 'letting nature take its course', for example. Yet to omit to treat a patient with the foreseen consequence of hastening death is potentially the crime of murder. Parents who knowingly agree to such a course may be co-conspirators. ${ }^{4}$ The circumstances in which it might be in a neonate's best interests to be allowed to die therefore urgently require clarification.

\section{The legal approach to determining best interests}

The first situation where selective nontreatment is legally acceptable occurs when a neonate will inevitably die in the short term whatever therapy is provided. Authority for this is found in $\operatorname{Re} C$ where the court held that non-treatment was in the best interests of a hydrocephalic preterm infant on the verge of death. ${ }^{5}$

The second legal justification for selective non-treatment arises when brain damage is so severe that death would arguably be preferable to life. This view derives from $\operatorname{Re} J$ which concerned an infant suffering from severe brain damage entailing multiple serious disabilities blindness, deafness, spastic quadriplegia, and severe retardation. ${ }^{6}$ The legal importance of this case cannot be overestimated as this infant was neither dying nor necessarily in severe pain.

The final instance in which selective nontreatment appears lawful stems from the 
neonate's pain and suffering per se. There will come a point when it is accepted that the benefits of life with treatment fail to outweigh the burdens. This would be so even though, again, the infant might not be in a terminal state. In the decision of $\operatorname{Re} B$, for example, the court held that the prospect of a 'demonstrably awful life' was sufficient for selective nontreatment to be appropriate. ${ }^{7}$ Here, the court consented to treatment on behalf of a baby with Down's syndrome and a duodenal atresia. It thus implicitly suggested that only conditions worse than Down's syndrome should be considered for non-treatment.

\section{Making moral sense of the legal definition of best interests}

The preceding legal judgments do not explicitly articulate moral arguments to justify their conclusions about what constitutes an individual's best interests. The central moral question is at what point, if any, does the prognosis of an individual become so poor that it is morally unacceptable to prolong life? There are several ways of arguing that such a line can be drawn. Some of these arguments contain inconsistencies that we cannot explore here. ${ }^{8}$ Rather we will focus on the one justification that appears both internally consistent and compatible with existing case law.

Few people now really believe in the absolute sanctity of human life. Selective nontreatment is widely accepted as an appropriate option in relation to some conditions (for example, anencephaly). ${ }^{9}$ The real question concerns the circumstances in which it can be coherently argued that neonates lose the right to have their lives prolonged through medical or surgical intervention. To answer this we must ask what sorts of beings can reasonably be said to have rights at all?

The possession of human rights depends upon the ability to exercise them - to make choices and to act in accordance with perceived needs and preferences. To have, say, the right to free speech would be unintelligible without the ability to decide what to communicate. The possession of human rights, therefore, depends upon having these attributes.

More specifically, to be able to do anything in the preceding terms, individuals must possess self awareness. ${ }^{10}$ Similarly, they must have the capacity to formulate aims and accompanying beliefs about how to achieve them. This further presupposes the basic ability to use language, the competence to reason, and the emotional confidence to act and interact with others. ${ }^{11}$

All of these capabilities must be present over sustained periods of time, enough for individual human identity - 'personhood' - to be both formed and expressed. Of course, the fact is that even healthy infants do not possess these attributes and therefore are not persons in these terms. However, they do have the potential for personhood because ordinarily, after a few years, they will develop them. It is upon this that their right to life saving health care is founded, when and if they become ill. ${ }^{12}$
By contrast, some infants are so mentally and physically disabled that this potential is compromised. The difficulty still remains of establishing the point at which such infants so lack these capabilities that their human rights are called into question.

This problem can be addressed through identifying the sorts of conditions in which infants are so disabled that they can never become persons with the rights which accompany this status. ${ }^{13}$ Roughly, there are three:

(1) Conditions judged to be terminal in that death will pre-empt the potential for future personal development.

(2) Conditions that entail so much retardation through neurological damage that the development of self awareness and intentional action will be virtually impossible.

(3) Conditions where cognitive function may be compatible with a small level of self awareness. However, the severity of the accompanying physical disability is such that there is no prospect of the infant ever being able to act on his or her own behalf.

These conditions raise few moral problems, provided that we accept the arguments put forward about human rights and the potential for personhood.

There is a fourth possibility - usually associated with spina bifida - which raises more controversial and indeterminate moral issues:

(4) Conditions in which neurological status may be compatible with high levels of cognitive function but where very severe physical disability is likely. This must also be accompanied by persistent pain and suffering associated both with the physical condition itself and the fact that effective clinical management will entail recurrent invasive treatment throughout childhood.

Here the necessary mental attributes of personhood may partially or completely evolve. However, their development may also be gravely compromised by sustained pain and distress. Even so, our preceding arguments appear to dictate that the potential autonomy of such children should be respected. When they become mature enough to decide for themselves, they can always commit suicide if that is their choice.

The problem is that even though they may have no significant mental retardation, the suffering they will endure throughout childhood may appreciably impair their autonomy. This is aside from other disastrous effects on their quality of life. For example, evidence suggests a high incidence of severe depression among adult patients with serious spina bifida. ${ }^{14}$ These young people may not therefore be in a position to exercise their right of choice in anything like the objective and rational way in which the preceding argument presupposes.

In reality, their capacity to do so will depend upon practical access to emotional and educational support. This is usually provided by intensive and sometimes costly parental or institutional care. Where access to such care is judged unlikely then it can be argued that to continue to treat amounts to an immoral 
gamble with the child's best interests. Infants can make no choices for themselves. The fact is that if treated they will probably suffer a childhood that most clinicians and parents would regard as unacceptable. ${ }^{9}$

This said, it must also be recognised that the legal force of such reasoning is unclear. On the one hand, we have seen that the judgment in $\operatorname{Re} B$ endorsed selective non-treatment when a child faces a demonstrably awful life. Similarly, in 1981, the Director of Public Prosecutions declined to initiate proceedings against doctors who allowed a severely damaged spina bifida infant to die. ${ }^{15}$ It is well known that since this case, selective non-treatment has regularly occurred under similar clinical circumstances without threat of prosecution.

On the other hand, no court has yet addressed the acceptability of selective nontreatment when the child's primary handicap is physical. At least one of Lorber's criteria for non-treatment falls into this category and, again, has consistently been acted upon for over a decade. ${ }^{16}$ Yet the fact remains that we are discussing children who are potential bearers of rights in precisely the cognitive terms we have outlined. The urgency of the need for further legal clarification on this matter cannot be overestimated, especially in light of the common practice of sedation and demand feeding.

It is no accident that the preconditions for having a demonstrably awful quality of life are generally the same as those for not having the potential for claiming human rights. This is why selective non-treatment decisions do not feel as if they infringe the rights of the neonates on behalf of whom they are made. In short, even if our arguments about rights and personhood are not explicit in the discourse of clinicians, they either already do, or at least should, inform it.

\section{The decision making process}

Non-treatment issues arise when the benefit of continued life prolonging treatment for an infant becomes open to doubt for the reasons already discussed. Parents then need to be consulted to obtain their specific agreement not to proceed. The initial general consent to treatment which they should have given does not cover this situation. At this stage, therefore, they must be provided with the information necessary to make an informed choice. It is not acceptable to attempt to 'spare them' the agonising decisions involved by obscuring either the truth or areas of uncertainty in the prognosis. This should not preclude recommending one course of action as being the best of those available.

When should selective non-treatment options be placed on the agenda? Chiswick has powerfully argued that there must be objective clinical evidence that a neonate's prognosis is sufficiently bad so as to justify considering non-treatment. ${ }^{17}$ While statistics should never overrule clinical discretion, around an $80 \%$ risk of a very poor outcome is often the point at which the ordinary curative goal of treatment begins to be questioned. This is morally acceptable because by adopting such a high threshold of risk, the presumption is still clearly in favour of preserving life. ${ }^{18}$

Thus whenever neonates are at all viable, it is vitally important that every effort is made to allow a course of clinical assessment to begin. Their best interests call for as accurate a determination of prognosis as possible. In the face of the uncertainty that may exist, it is important that adequate time is taken for a high degree of consensus to be achieved among the health care team.

The more rigorous the demand for prognostic accuracy, however, the more often stressful decisions about withdrawal of treatment will have to be made. In such circumstances, it might help to remember that there is no moral or legal difference between a decision not to commence treatment and to withdraw it when it is understood that death will be the consequence of either action. No matter how emotionally difficult these decisions may be, it must be stressed that the duty of care is owed to the infant and not to anyone else.

There will be some cases where clinicians and parents alike are convinced that the prognosis is so poor that the continuation of active treatment would be immoral. In others, they may disagree. Such disagreement may occur in three situations.

First, despite the infant's poor condition, clinical opinion is that non-treatment cannot be justified at that time. Here, if parents persistently refuse to consent to further intervention then children should be treated immediately if their lives are at risk. Otherwise, they should be made wards of court and treatment should continue if the judge agrees. The justification for immediately overriding parental wishes is the moral and legal imperative of saving the child's life - the so-called 'doctrine of necessity'. ${ }^{19}$ As regards wardship, the right of proxy is removed from parents because of its apparent improper exercise.

Second, clinical consensus may be that the prognosis is so bad that continued treatment would be against the infant's best interests. Here, if parents insist on life prolonging intervention, then there is no moral reason which necessitates compliance. Indeed, we have argued that when the prognosis is extremely poor, it is morally incumbent on clinicians to refuse such treatment. The infant has no right to it and expending resources in this way might well jeopardise treatment options for others who do possess this right. Legally, the situation has been clarified by $\mathrm{Re} \mathrm{J}$ where the Court of Appeal ruled that doctors could not be compelled even by a court to give a neonate life saving treatment against their clinical judgment. ${ }^{20}$

The third situation where disagreement may arise is when the prognosis is poor but indeterminate enough to give the infant the benefit of the doubt. In this circumstance, clinicians may agree to continue to treat, despite their inclination not to. This is because the degree of commitment demonstrated by parents in choosing to care for a seriously disabled child is an 
important determinant in fostering whatever limited potential that that child has. Thus, parental choice, one way or the other, should be respected when there is appreciable doubt about the application of the principle of 'best interests'.

It is therefore not being suggested that criteria for non-treatment like the above will be easy to apply in every individual case. Again, there will often be ambiguity as to the correctness of some non-treatment choices. In the face of such uncertainty - especially when there is disagreement among the health care team - the force of the argument shifts from issues of moral substance to those of procedure. If the 'right' answer is illusive then it becomes crucial for all concerned to believe that decisions have been reached in a fair and rational manner. In order to achieve this aim, the following procedures are suggested.

Judgments about non-treatment should only be taken by consultant neonatologists. The gravity of these decisions demands that they be made by no one but the most senior clinicians. The only exception to this rule concerns cardiopulmonary resuscitation. For obvious logistical reasons, treatment can be withdrawn without the approval of a consultant when a more junior clinician is supervising a resuscitation procedure that has clearly failed. ${ }^{21}$

Further, senior nursing staff and, where appropriate, other clinicians should be consulted before selective non-treatment decisions are taken. The date and time of decisions to withhold or withdraw life sustaining treatment should always be prominently entered into both the medical and nursing notes, along with the clinical justification and documented parental consent where applicable. This should ensure that the whole health care team are aware of and understand any non-treatment decision that may eventually be reached.

\section{The aftermath to selective non-treatment decisions}

Once it has been decided that life should not be prolonged, the doctor's duty of care does not end. It then becomes an obligation to 'treat for dying'. ${ }^{22}$ Thus the infant must be made comfortable with sufficient analgesia and nursing care. This said, the extent of the duty to provide artificial hydration and nutrition is more controversial. Premature babies commonly require nasogastric feeding for long periods. As regards the law, it was decided in the Bland case that artificial feeding was a medical treatment and could therefore be withheld if judged by doctors to be unbeneficial to the patient. ${ }^{23}$

Despite this, neonatal intensive care teams would at present only consider the withdrawal of nutrition very reluctantly, even when it might seem in the infant's best interests. Nasogastric feeding is very common and is seen as standard care. Yet given Bland, its withdrawal can still be morally and legally justified in accordance with the best interests criterion - say for cases of severe congenital malformation in which early death is certain in any event.
There is a need to be consistent in relation to selective non-treatment. Once the decision is made that sustaining life is against the neonate's best interests, all life prolonging treatments should be withheld. Distinctions between so-called 'ordinary' as opposed to 'extraordinary' therapies should be avoided. Thus antibiotics, resuscitation and even, on occasion, artificial feeding or hydration should be treated alike. The only exception is where a palliative purpose is served by employing a treatment that will incidentally lengthen life.

\section{Conclusion}

We hope that the above proposals offer a basis for the formulation of written guidelines on withholding and withdrawing treatment in neonatal medicine. These could then be adopted by individual neonatal units. It is sometimes argued that guidelines are inappropriate for selective non-treatment within neonatal care. There are suggestions that clinical discretion will be undermined in an area where it is most needed. The sensitive nature of the deliberations in neonatal units requires a delicate approach. There are worries that legalistic rules will be too heavy handed, disrupting the balance between parental and clinical responsibility in decision making.

These are understandable reservations, ones which the preceding framework seeks to accommodate. Its key proposals are stated in wide terms that allow different clinical circumstances to be assessed both morally and legally. The primary objective of any written policy should not be an attempt to anticipate and legislate for every eventuality. Rather, the intention should be to provide a broad statement of the ethical and legal principles that should inform good clinical decision making.

The fact is that when making selective nontreatment decisions clinicians already employ a variety of 'rules of thumb' based largely upon personal conviction. Were neonatal units encouraged to adopt public policies justifying non-treatment then this would inevitably focus attention on their moral and legal acceptability. We hope that the arguments developed in this paper will be seen as a useful guide for this purpose.

Our thanks to S Benton, K L Costello, D P Drake, M Griffiths, R J Harris, V Mendham, G J A I Snodgrass, and C Wood; special thanks to $S$ Kempley. We are also grateful to the King's Fund for the fellowship which funded this research.

1 Duff RS, Campbell AGM. Moral and ethical dilemmas in the special care nursery. $N$ Engl $\mathcal{F}$ Med 1973; 289: $890-4$.

2 Anonymous. Dr Leonard Arthur: his trial and its implications [Editorial]. $B M \mathcal{Y F}$ 1981; 283: 1340.

3 Sidaway $v$ Board of Governors of the Bethlem Royal and the Maudsley Hospital [1985] 2 WLR 480, HL.

4 Kennedy I, Grubb A. Medical law: text and materials. London: Butterworths, 1990: 936-41.

$5 \operatorname{Re} C$ (a minor) [1989] 2 All ER 782, CA

6 Re J (a minor) [1990] 3 All ER 930, CA.

$7 \mathrm{Re} B$ (a minor) [1981] 1 WLR 1421, CA

8 Weir RF. Life-and-death decisions in the midst of uncertainty. In: Caplan AL, Blank RH, Merrick JC, eds. Compelled compassion. Totowa: Humana Press, 1992. $1-33$.

9 Kuhse H, Singer P. Should the baby live? Oxford: Oxford University Press, 1985: 118-39, 141-6.

10 Harris J. The value of life. London: Routledge Keegan and Paul, 1985: 7-27.

11 Doyal L, Gough I. A theory of human need. London: Macmillan, 1991: 49-75. 
12 Doyal LT. Neonatal surgery and the morality of selective non-treatment. In: Freeman N, Burge D, Griffiths $M$,
Malone P, eds. Surgery of the newborn. London: Churchill Malone P, eds. Surgery of the
Livingstone, 1993 (in press).

13 Doyal L. Needs, rights and the moral duties of clinicians. In: Gillon R, ed. Principles of health care ethics. London Wiley, 1993 (in press).

14 Dorner S. Adolescents with spina bifida: how they see their situation. Arch Dis Child 1976; 51: 439-44.

15 Brazier M. Medicine, patients and the law. London: Penguin Books, 1992: 316-7.

16 Lorber J. Ethical problems in the management of myelomeningocele and hydrocephalus. $\mathcal{f} R$ Coll Physician Lond 1975; 10: 47-59.

17 Chiswick M. Withdrawal of life support in babies: deceptive signals. Arch Dis Child 1990; 65: 1096-7.

18 Rhoden NK. Treating baby Doe: the ethics of uncertainty. Hastings Cent Rep 1986; 16: 34-42.

19 Brazier M. Medicine, patients and the law. London: Penguin Books, 1992: 90-1.

20 Re J [1992] 9 BMLR 10, CA.

21 Doyal L, Wilsher D. Withholding cardiopulmonary resuscitation: proposals for formal guidelines. BMF 1993; 306 1593-6.

22 Kennedy I. Treat me right. Oxford: Clarendon, 1988: 146-9.

23 Airedale NHS Trust v Bland [1993] 1 All ER 858, HL

\section{Commentary}

More important than guidelines themselves are the principles which underlie them and nowhere is this more true than in the sensitive field of medical ethics. Doyal and Wilsher's paper explores some principles which may govern future guidelines for the provision of life prolonging treatment in neonatal medicine, focusing on moral arguments.

Most would agree that when death is perceived to be inevitable, and when it is felt that the baby has entered the process of dying, then the provision of life support measures is a futile and pointless exercise. In practice these measures will already be in place and their very failure heralds the inevitability of death. The issue is normally one of withdrawal of ventilatory support with the anticipation of death in minutes or several hours. Guidelines for practice would have to include the medical criteria which point to a baby entering the process of dying.

The issue which really tests our moral judgment, and the one which Doyle and Wilsher bravely address, is whether there are circumstances where death is not inevitable, yet infants may none the less lose the right to have their lives prolonged. The authors focus on the concept of the 'potential for personhood' and seek to identify conditions in which infants are so disabled that their possession of human rights may legitimately be called into question because they will never develop the potential for self awareness, intentional action, and the ability to act on their own behalf.

Those of us who regularly see in our clinics very severely handicapped children may be aware of a sense of 'correctness' which sometimes drives us, against our better judgment, to complicity with parents and other health workers when we are asked to initiate a range of services that are unlikely to yield any material benefit for the child yet might well satisfy parental needs.

Against this background the idea of infants being 'so disabled that they can never become persons with the rights which accompany this status' will be abhorrent to many paediatricians, especially those who are prominent in championing the rights of children. Yet this must be seen in context - the authors are arguing that there is no moral obligation to keep a newborn baby alive by medical science if the result will be an infant so disabled. Indeed, they wish to prevent this ultimate state of affairs. Of course, given that such disabled children do exist then they have the rights of any other person (except the right to life prolonging treatment).

What we have here is a coherent moral argument (even if some might not share their position) but a major problem in translating it into neonatal practice. In essence, by the time it has become clear that an infant has a very high risk of becoming so disabled the opportunity to exercise judgment and choice in the provision of life prolonging treatments has often passed. Probably the most common scenario is the very preterm baby or the perinatally asphyxiated term baby who is receiving assisted ventilation (where there were no reasonable grounds for denying such treatment when it was initiated). As the authors say the prognosis must be determined as accurately as possible, and adequate time must be allowed to achieve consensus. Yet the baby may have been successfully weaned from the ventilator before this point is reached.

While I am comfortable with the idea that withdrawal of assisted ventilation can in some cases present itself as a 'window of opportunity' which is morally acceptable I am uneasy about too broad an interpretation of 'treat for dying'. Assisted ventilation is surely an extraordinary measure of care in so far as we expect babies to breathe without assistance, whereas all newborns require a caregiver for nutrition, hydration, and maintenance of a normal body temperature. I see a real moral difference between hastening death of a newly born baby by withdrawing ventilatory support and doing so by withholding fluids or nutrition.

Examples of withholding or withdrawing treatments other than assisted ventilation in order to allow a baby to die are uncommon on neonatal units today. Doyal and Wilsher's paper acknowledges some very difficult issue surrounding surgical treatments of congenital abnormalities and the notion of 'pain and suffering'. Babies with multisystem abnormalities who pose these sort of ethical problems highlight the complex case to case variability of their circumstance. I suspect that their individuality might preclude guideline driven management unless the guidelines were so broad as to be of little material help.

Doyal and Wilsher touch on the question of resources when parents insist on treatment in the face of an extremely poor prognosis. Given the financial constraint that is common to all health services I wonder, especially with respect to the care of exceedingly preterm babies, whether future guidelines on life prolonging treatments can ever reconcile our duty to act in the infant's best interest with our broader responsibilities to ensure a wide provision of service.

M L CHISWICK North Western Regional Perinatal Centre, St Mary's Hospital, Manchester M13 OfH 